\title{
Using RGB-D sensors and evolutionary algorithms for the optimization of workstation layouts
}

\author{
Jose Antonio Diego-Mas ${ }^{\text {a, }}{ }^{*}$, Rocio Poveda-Bautista ${ }^{\text {b }}$, Diana Garzon-Leal ${ }^{c}$ \\ ${ }^{a}$ I3B, Institute for Research and Innovation in Bioengineering, Universitat Politècnica de València, Camino de Vera s/n, 46022 Valencia, Spain \\ ${ }^{\mathrm{b}}$ Engineering Projects Department, Universitat Politècnica de València, Camino de Vera $s / n, 46022$, Valencia, Spain \\ ${ }^{\mathrm{c}}$ Universidad del Bosque, Av. Cra 9 No. 131 A - 02, Bogotá, Columbia
}

\section{A R T I C L E I N F O}

\section{Article history:}

Received 14 June 2016

Received in revised form

9 January 2017

Accepted 19 January 2017

Available online 31 January 2017

\section{Keywords:}

RGB-D sensors

Workstation layout

Genetic algorithms

\begin{abstract}
A B S T R A C T
RGB-D sensors can collect postural data in an automatized way. However, the application of these devices in real work environments requires overcoming problems such as lack of accuracy or body parts' occlusion. This work presents the use of RGB-D sensors and genetic algorithms for the optimization of workstation layouts. RGB-D sensors are used to capture workers' movements when they reach objects on workbenches. Collected data are then used to optimize workstation layout by means of genetic algorithms considering multiple ergonomic criteria. Results show that typical drawbacks of using RGB-D sensors for body tracking are not a problem for this application, and that the combination with intelligent algorithms can automatize the layout design process. The procedure described can be used to automatically suggest new layouts when workers or processes of production change, to adapt layouts to specific workers based on their ways to do the tasks, or to obtain layouts simultaneously optimized for several production processes.
\end{abstract}

๑ 2017 Elsevier Ltd. All rights reserved.

\section{Introduction}

RGB-D sensors ${ }^{1}$ are devices capable of detecting the distance to the objects found in a scene. They are basically composed of an infrared laser transmitter that projects a speckle pattern on its environment, and an infrared camera that captures the projected pattern. The data obtained by the infrared camera is compared with reference standards, allowing estimating the distance of each image pixel to the sensor (Garcia and Zalevsky, 2007; Henry et al., 2012; Khoshelham and Elberink, 2012). In addition, the device has a conventional RGB camera, so pixel color data is added to distance data.

This technology is not new. There are devices able of capture the depth of a scene from the late twentieth century. However, two features of the new RGB-D sensors have contributed to their increasing use in a wide range of fields and applications. Firstly, the

\footnotetext{
* Corresponding author.

E-mail addresses: jodiemas@dpi.upv.es (J.A. Diego-Mas), ropobau@dpi.upv.es (R. Poveda-Bautista), dgarzonl@unbosque.edu.co (D. Garzon-Leal).

1 Depth sensors are known by several names (Flash Lidar, time-of-flight camera, ranging camera, range sensor ...). In this work we will use the term RGB-D sensors because this is currently the most common denomination for this kind of devices.
}

new RGB-D sensors have a very low cost compared to older devices (approximately \$200 in 2016). Secondly, these new sensors can be used as 3D motion capture systems because the software that controls the sensor provides information about the position of the joints of recognized users present in the scene (skeleton data) in close to real time. Position of body parts are obtained from depth data using a randomized decision forest algorithm, learned from millions of training examples (Han et al., 2013).

In 2010 Microsoft released the Kinect RGB-D sensor. Simultaneously other sensors appeared on the market such as the ASUS Xtion. Since then, the availability in the market of RGB-D sensors fostered the development of promising approaches to usual problems in many areas like object recognition, 3D reconstruction, augmented reality, image processing, robotic, or human-computer interaction. In the field of ergonomics, early research on the uses of the new RGB-D sensors focused on whether the accuracy of the data obtained allowed their use as markerless motion capture devices (Bonnechère et al., 2013a, 2013b; Clark et al., 2012, 2013; Destelle et al., 2014; Dutta, 2012; Fernández-Baena et al., 2012; Nixon et al., 2013; Obdrzálek et al., 2012; Pfister et al., 2014). The results of these studies suggest that the accuracy of the sensors is only slightly lower than that of more expensive devices, but reliable enough to be used for postural assessment. Other studies focused 
on the use of RGB-D sensors in traditional techniques for ergonomics assessment like RULA (Haggag et al., 2013; Plantard et al., 2015), OWAS (Diego-Mas and Alcaide-Marzal, 2014) or NIOSH lifting equation (Patrizi et al., 2015; Spector et al., 2014).

Although the findings of these studies seem promising, and RGB-D sensors can be used like a tool to support the tasks of ergonomists, its technology is not enough developed to replace human experts, and certain aspects need further research to use RGBD sensors in real working environments. For example, these devices are good tracking system when the subject is facing the sensor or is in the range of $\pm 40^{\circ}$. Otherwise, data reliability decreases significantly (Diego-Mas and Alcaide-Marzal, 2014). Occlusion and selfocclusion are major problems too. The position of a joint that is not visible to the sensor is inferred. Its position is calculated from surrounding joint data rather than being directly captured (NUI, 2013) dramatically diminishing the reliability of the data. These situations are very common in real scenarios, where the worker could handle large objects that occult body parts to the camera, some part of the body could be behind other part or, simply, the worker moves outside the sensor field of view. Some researchers try to solve this problem using multiple sensors oriented at different angles relative to the tracked subject (Berger et al., 2013). On the other hand, body tracking may not accurately obtain lower body kinematic data (Yang et al., 2015), and joint rotations are not correctly captured or not captured at all for the peripheral limbs or the head. Moreover, tracking algorithms usually employed may cause the length of body limbs not to be constant over time (NUI, 2013).

In 2014 Microsoft released an improved version of Kinect. Kinect V.2 has better resolution for the depth sensor and its skeletontracking algorithm (named body-tracking in this version) is able to track more body joints. The comparison between both sensors developed by Xu and McGorry (2015) concluded that the accuracy of joint center location identification is not substantially improved in Kinect v2. Therefore, given the current state of this technology, the use of RGB-D sensors in any real applications should take the limitations of these devices into consideration.

This work presents the use of RGB-D sensors (Microsoft Kinect тм) and Genetic Algorithms (GA) for the automatic rearranging of working areas to optimize the reaches for working elements and the movements of the worker. The approach presented allows the automated optimal distribution of the elements present in the working plane based on ergonomics and production criteria. To achieve this, a RGB-D sensor detects the movements of the worker's hands when performing reaches during the development of their task. The data recorded by the sensor over a period of time are used by a GA for obtaining a new distribution based on criteria formerly set by the designer. The algorithm also considers the geometric constraints of the working plane and of the elements to be distributed on it. This procedure can be applied to assembly workstations, office workstations, packing workstation, supermarket check stand workstations, or any task in which the worker's activity is performed on a plane and in a limited area. RGB-D sensors are suitable for this application as they only have to detect the position of the worker's hands; occlusion can be avoided by properly placing the sensor; the worker remains all the time in the field of view of the camera and is located opposite the sensor.

Besides obtaining optimum layouts from the RGB-D sensor data, the system can be used for the constant monitoring of the workstation. The GA continually analyses the sensor data for obtaining new layouts to better adapt to changes in volumes or production systems, or to changes in workers' positions. In this way, the system will alert the production engineers about a new distribution better adapted to the new situation, who will then decide whether to implement it.
The following sections describe the developed procedure and its application to a case study in a workstation for the assembly of small components. In Section 2, ergonomic and productive criteria for proper assembly workstation layout are described. Section 3 shows the use of RGB-D sensors for data recording and their use in GA for finding optimal layouts based on the sensor data. In Section 4, the system is applied to a case study. The results and limitations of this approach are discussed in Section 5. Finally, some conclusions are drawn in Section 6.

\section{Layout of assembly workstations}

In assembly workstations workers assemble parts of products to obtain finished products or sub-assemblies. The parts to be assembled are in the worker's surroundings, who must reach and assemble them usually following certain order and using the right tools. The assembly workstations can be part of an assembly line or independent posts. According to the Department of Labor of the United States, in 2015 there were 1,834,000 workstations of this kind in the USA (Occupational Outlook Handbook, 2015). Although the general trend is to automate the assembly process, there are many assembly workstations operated by workers due to technical problems or the high cost of automation.

In these workstations, a poor layout of the working elements (usually arranged over a workbench) will result in low efficiency, premature fatigue, health problems and mistakes (Sanders and McCormick, 1993). The designer must determine the best locations for working elements (parts, tools, equipment, etc.) within the working area, taking into consideration different productive and ergonomic criteria which may even be conflicting with each other (Battini et al., 2011; Das and Sengupta, 1996; Deros et al., 2011; Saptari et al., 2011; Shikdar and Al-Hadhrami, 2012, 2007; Shikdar and Al-Kindi, 2007). For this reason designers usually use intelligent calculation techniques such as GA, neural networks, fuzzy logic or knowledge-based systems. A review of these techniques could be found in Zha and Lim (2003).

Some ergonomic design principles can be drawn from the studies mentioned above. For example, frequently used working items should be kept close to the worker. If products must be assembled in a specific order, working items that are used in combination or that are close in the assembly sequence must be kept together. Placing working items in areas that require extra effort from the worker to reach them should be avoided; if total avoidance is not possible, at least those less frequently used working elements should be placed in these areas. Heavy working items should be placed in an easy-to-reach area that requires minimal operator movement, and does not require bending or twisting to move from the access point to the install point. Parts requiring inspection or precision handgrip should be placed near the worker. The zone where the parts are assembled should be located in front of the worker, avoiding prolonged work periods in areas requiring neck or trunk twisting. Parts or tools to be handled with the right or left hand should be placed in the corresponding part of the working area, avoiding the hands crossing the worker's sagittal plane to pick them up. Other design principles to be considered regarding item placement in normal and maximum working areas (Das and Behara, 1995) can be seen in Das and Sengupta (1996).

There are several techniques for optimizing workplace distribution (Zha, 2003). As a general rule, it is necessary to analyze the arrangement of the working elements in the workplace and workers' movements while performing their tasks. The data obtained are analyzed using specific software (Santos et al., 2007), CAD systems and heuristic or metaheuristic techniques (Zha, 2003) to obtain the best layout. The capture of the worker's reaches can be 
performed in different ways. For example, recording the task using a video camera for further frame-to frame analysis (Shinde and Jadhav, 2012), using three-dimensional motion capture systems (Best and Begg, 2006) or inertial measurement systems (Brodie et al., 2008). In general, these systems have limited accuracy or are difficult to use in real-world applications due to complexity, bulk and space requirements, considerable initial investment to purchase the equipment, high costs of maintenance and the needing of employ highly trained technical staff (Trask and Mathiassen, 2012).

In current production systems changes in products or production volumes are frequent to adapt to market demand. Even, different products can be processed in the same workstation. Therefore, workstation layout should be developed simultaneously considering several production processes, or to be easily adapted to potential changes in the manufacturing process. In addition, a particular workstation can be operated by several workers in different shifts. Even if the assembly order is fixed, there are anthropometric differences between operators, as well as different ways of performing each task. It is therefore advisable that workstation layout considers all workers who occupy the post, or even, set customized layouts for each worker. It might even be advisable to set specific layouts for workers with health problems that should avoid performing certain movements.

For these reasons, the processes of data acquisition, information analysis and layout design should be simplified. The use of RGB-D sensors for data recording and metaheuristics, like GA, for optimal layout design based on sensor data allows the automation of this process. Moreover, it is a low cost system, requiring little space, low maintenance costs and not highly qualified staff.

\section{Genetic algorithms for solving facilities layout problems}

To obtain the best layout of the items in the working area can be considered a Facility Layout Problem (FLP) (Kusiak and Heragu, 1987). A FLP considers the layout, with no overlaps, of a group of elements of known and unequal areas in a flat area of given dimensions. The layout must be obtained in such a way that costs related to the interactions between the elements are kept to a minimum. Finding the optimal layout of workstations can be considered a case of FLP.

Solving a FLP is a common issue in many types of problems (plant layout, memory allocation, packing ...) (Drira et al., 2007; Dyckhoff, 1990; Islier, 1998). When the number of objects to be distributed and the number of constraints to consider is high it is not possible to find exact procedures to solve the problem (Amaral, 2006). Commonly used techniques are simulated annealing (Saifullah Hussin and Stützle, 2014), tabu search (James et al., 2009), ant algorithms (Hani et al., 2007; Jain and Sharma, 2005), memetic algorithms (Merz and Freisleben, 1999), particle swarm optimization (Önüt et al., 2008), genetic algorithms (Diego-Mas et al., 2009; El-Baz, 2004) or neural networks (Hasegawa et al., 2002; Zha, 2003).

Of the various techniques for solving the FLP, those based on GA have given good results (Srinivas and Patnaik, 1994), and within this group, those based on the slicing tree structure (Tam, 1992), are efficient in the search for geometrically acceptable solutions. GA perform a stochastic guided search based on the evolution of a set of structures (chromosomes) as it occurs in natural species (Goldberg, 1989). GA start with a set of problem solutions (initial population) represented by chromosomes (finite arrays) randomly generated. Each chromosome is evaluated using a fitness function to determine its suitability for the requirements of the problem. The initial population undergoes several transformations so as to generate a new set of solutions that inherit the best characteristics of their predecessors. These transformations are guided by some genetic operators (usually selection, crossover and mutation), which combine or modify the chromosomes representing the solutions. This process is repeated until reaching a previously set stop criterion, for example, a certain number of iterations is reached, or a certain number of iterations without a new best solution have been performed.

For the layout obtained to be really applicable the imposed geometrical restrictions must be strictly respected. Solutions that do not conform to these limits are considered unacceptable. For this reason, in this work we propose to use the GA suggested in DiegoMas et al. (2009). This GA allows solving facility layout problems with strict geometric constraints. A detailed description of its operation can be found in Diego-Mas et al. (2008). This GA is primarily intended for optimizing industrial facilities layouts; however, it is possible to adapt it to be used for optimizing workstations layouts by including in its fitness function new terms to consider ergonomic criteria. Section 4.3 will show how the fitness function has been modified to operate with the information acquired from an RGB-D sensor and to consider ergonomic criteria.

\section{Material and methods}

The system proposed in this work uses an RGB-D sensor to detect the positions of the worker's hands while performing the task and a GA that calculates the best workstation layout based on the criteria set by the designer. This process is developed in three stages. The first stage involves collecting information about the workstation under analysis (e.g. the number and dimensions of the working elements to distribute and the dimensions of the working area). In the second stage, an RGB-D sensor detects the positions of the worker's hands while performing the task. Finally, the sequence of the positions of the hands is sent to the GA that calculates the best workstation layout. Specific software consisting of three modules was developed to control the system. The first module (data module) allows data input about the task to analyze. The second (tracking module) controls the RGB-D sensor and saves the sequence of movements. The third (calculation module) implements the GA for optimum layout design.

\subsection{System configuration}

The first stage involves collecting information about the workstation that is input into the first module of the software. The data correspond to the dimensions of the working area and the working elements to be distributed in it. The working area is the area in which the worker performs his task and where the different working elements will be distributed. Generally, it matches the dimensions of the worktable or workbench. The working area needed data are width $(\mathbf{W})$ and height or depth $(\mathbf{H})$.

The working elements to distribute (hereinafter referred to as items) are the different elements that take up space in the working area. Items can be parts, bins, tools or any space for the worker to develop some kind of activity. The number of items to be distributed will be called $\mathbf{n}$. The areas occupied by the items are the space required for the activity associated with them can be performed normally. The areas of the items are considered to be rectangular and of flexible geometry, which means that the geometric ratio (depth divided by width) of the area allocated to each item may vary within certain limits (geometric constraints).

Let $\mathbf{a}_{\mathbf{i}}$ be the area occupied by each item $\mathbf{i}$, and $\mathbf{r}_{\mathbf{m i n} \_\mathbf{i}}$ and $\mathbf{r}_{\mathbf{m a x} \mathbf{i}}$ the minimum and maximum geometric ratios allowed for each item i. Fig. 1 shows the possible shapes of a flexible geometry item; Item area remains constant while the ratio between item depth and width varies within certain limits $\left(\mathbf{r}_{\min }\right.$ and $\left.\mathbf{r}_{\mathbf{m a x}}\right)$. For the definition 


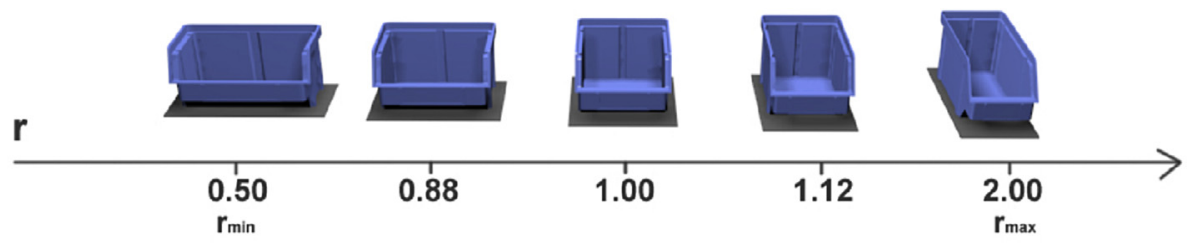

Fig. 1. Range of variation of the shape of an item given min and max geometric ratios.

of the geometric ratios allowed for an item it should be considered that certain activities require a specific orientation. For example, Fig. 1 shows that with ratios lower than 1 item orientation is horizontal, while ratios higher than 1 allow vertical item orientations.

Finally, information regarding the position of each item in the initial layout, ie, at the time of data collection, will be provided. Thus, for each item $\mathbf{i}$, the coordinates of two opposite corners of the rectangle occupied by the item are calculated. Fig. 2 shows these vertices $\left(\left[\mathrm{x}_{1}, \mathrm{y}_{1}\right],\left[\mathrm{x}_{2}, \mathrm{y}_{2}\right]\right)$ for one item.

\subsection{RGB-D sensor configuration and data acquisition}

The sensor used in this work was Microsoft Kinect. This RGB-D sensor calculates the positions of the joints transforming the coordinates into an array of data. The $\mathrm{x}, \mathrm{y}$ and $\mathrm{z}$-axes are the axes of the depth sensor. This right-handed coordinate system places the sensor at the origin with the positive z-axis extending in the direction of the sensor's camera. The positive $y$-axis extends upward, and the positive $x$-axis extends to the left (NUI, 2013).

The RGB-D sensor should be placed in a position where the worker's upper limbs are visible, avoiding occlusion due to the presence of objects in the workstation (Fig. 2). The sensor will be placed as close as possible to the sagittal plane of the worker or in a range of $\pm 40^{\circ}$ (Diego-Mas and Alcaide-Marzal, 2014). With this sensor configuration, the lower limbs are unlikely to be detected by the sensor; however, this application only requires data of the upper limbs.

Using the information of the positions of the items on the working plane, the sensor control software defines a rectangular prism for each item. The prism base is the area occupied by the item, and its height is a parameter $(\mathbf{h})$, which may be the same for all items or different depending on the height of the objects occupying that position on the working plane (Fig. 2). These prisms are called Virtual Sensors (VS), and are defined by the coordinates

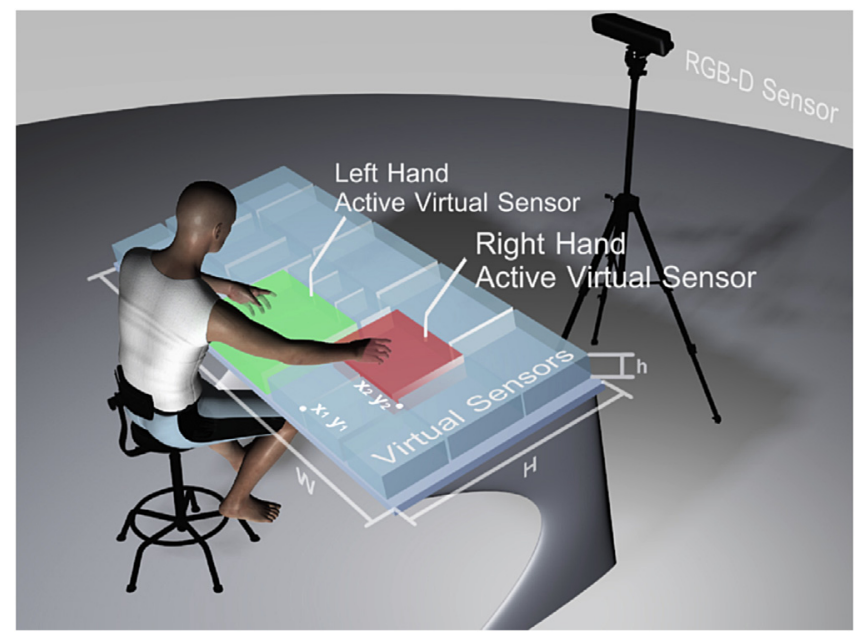

Fig. 2. Schematic view of the configuration of motion capture system. of its vertexes in the coordinate system of the sensor.

During data capture the sensor determines the position of the worker's hands. Kinect V1 skeleton-tracking algorithm is able to track two joints of the hand, one in the wrist and the other in the palm. Kinect V2 has introduced two new joints in the hand (handtip and thumb). The sensor control software can use any of these joints to detect the position of the hand. In this paper, the joint located in the center of the hand was used with satisfactory results.

When the sequence of the worker's movements varies (for example, when the assembly sequence is not fixed) it can be preferable to capture data from several work cycles. Thus, a layout can be obtained considering the variations in the sequence of movements. When the sequence of movements is fixed it suffices with the data obtained from only one work cycle.

When the coordinates of the position of a hand are inside one VS an event is recorded. This event indicates the time, the hand (left or right) and which VS has been activated. During access to a particular item, for example, to pick up a tool, the worker's hand can pass through other items. To prevent the recording of these intermediate items, the software only captures the event if the hand remains inside the VS for a time longer than a time threshold $\left(\mathbf{t}_{\mathbf{h}}\right)$.

By placing the sensor in a suitable position, it is unlikely to have occlusion of the upper limbs. However, the worker must handle objects with his hands while performing his task. Kinect body tracking algorithm has limitations in its capacity to detect hands' joints when handling objects. The sensor cannot track the hands position if the manipulated object is large. As a hypothesis of our work, there is not large objects that must be handled in the target workstation.

In addition, it is difficult to track the hands when their positions are very close to the table surface. To deal with this problem the $\mathbf{t}_{\mathbf{h}}$ parameter and the height (h) of the VS must be carefully defined by the evaluator. The proposed system only needs to detect when the hand reaches the VS and stays inside it during a time larger than $\mathbf{t}_{\mathbf{h}}$. Generally, when a worker must pick up an object placed in a given VS, he is not transporting other object on his hand. To ensure the detection before the object is picked up, the height of the VS must be larger than the height of the object. In this way, the hand is free of objects and it is not in contact with the working surface when it enters the VS, therefore, the system properly detects the access to the corresponding VS. The important point here is establishing a suitable $\mathbf{t}_{\mathbf{h}}$ value. Preferably, $\mathbf{t}_{\mathbf{h}}$ must be small, doing it easy to detect that the worker's hand has stayed inside the target VS enough time. However, if $\mathbf{t}_{\mathbf{h}}$ is too small, others VS crossed during the hand movement to reach the target VS, can be detected causing false positives.

Performing some tests over the workstation to be analyzed helps to establish the suitable $\mathbf{t}_{\mathbf{h}}$ value. In our tests, once the hand touches the object inside the VS, and depending on the size of the object, the sensor can infer the position of the hand using previous positions and the surrounding joints' positions. If the inferred position is inside the VS, the $\mathbf{t}_{\mathbf{h}}$ value is easily reached without using a very small value and avoiding false positives.

Finally, $\mathbf{t}_{\mathbf{h}}$ value should be set also considering the frequency at 
which the RGB-D sensor captures hand positions. Kinect obtains depth images at a rate of up to 30 frames per second. However, data processing to detect if hands are inside VS is time consuming. Therefore, the frequency of data acquisition and image processing depends on the number of VS. Obviously, $\mathbf{t}_{\mathbf{h}}$ must be greater than the time between two consecutive images (preferably there must be several images in a $\mathbf{t}_{\mathbf{h}}$ period).

\subsection{Calculation process}

After the time set for the collection of data by the RGB-D sensor, the data is sent to the calculation module to be used by the GA. The information consists of two arrays, one with right hand data and one with left hand data. The arrays have as many columns as VS were activated during the observation period and three rows. The first row indicates the VS code, the second row indicates the time when the VS was activated from the beginning of the observation period, and the third row indicates the time when the VS was deactivated. This data allows to know how many times a worker's hand reached an item and the number of times the worker's hand moved from one item to another.

As it has been aforementioned in Section 3, in a GA each chromosome is evaluated using a fitness function (or cost function) to determine its suitability for the requirements of the problem. Therefore, in our case, it is necessary to identify the criteria for measuring the quality of a workstation layout and to include them in the fitness function. As indicated in Section 2, many criteria can be considered. Which should be considered in a particular case depend on the characteristics of the workstation and the developed task. So that, the evaluator must determine the most suitable criteria for each particular problem including them in the cost function. Generally, a function for measuring the cost (C) of a layout in the GA proposed in Diego-Mas et al. (2009) may have the form of Equation (1) where $\mathbf{n}$ is the number of items to be distributed.

$C=C r \sum_{i=1}^{n} \sum_{j=1}^{n} d_{i j} r_{i j}+C g \sum_{i=1}^{n} i g_{i}$

In the second member of Equation (1) there are two terms. The first term (called Relational Cost) measures the cost derived from the distance between items. This cost depends on the distance between items in the resulting distribution layout $\left(\mathbf{d}_{\mathbf{i j}}\right)$ and the relationship among them $\left(\mathbf{r}_{\mathbf{i j}}\right)$. Although there are other options (Tompkins et al., 2010), the distance is usually measured as the euclidean distance between the geometric centers of the items. The $\mathbf{r}_{\mathbf{i j}}$ ratio must be defined in such a way that measures the need for closeness between two items in the workstation. For example, $\mathbf{r}_{\mathbf{i j}}$ value should increase with the number of worker's hand movements from item $\mathbf{i}$ to item $\mathbf{j}$ (data obtained from the RGB-D sensor). $\mathbf{r}_{\mathbf{i j}}$ value may also be higher if the objects handled between the items are heavy or if they require careful handling. Therefore, the first term of Equation (1) penalizes the layouts in which frequently accessed items are far of the worker, especially if these items are heavy objects or require special handling. This term minimizes the distance traveled by the worker' hands and the energy needed to develop the task.

The second term of Equation (1) (Geometrical Cost) measures the degree of compliance with the geometric constraints of the items in the layout. $\mathbf{i g}_{\mathbf{i}}$ value is 0 if the geometric ratio of an activity $\mathbf{i}$ is within the range $\left[\mathbf{r}_{\mathbf{m i n}} \mathbf{i}, \mathbf{r}_{\mathbf{m a x}} \mathbf{i}\right]$. If not, its value increases proportionally to the distance to the nearest end of that range. $\mathbf{C r}$ and $\mathrm{Cg}$ are weighting coefficients of each of the terms of the cost equation. These coefficients allow the designer to give more or less weight to each criterion.
These two terms (Relational and Geometrical costs) must be always present in the fitness function of the GA proposed in DiegoMas et al. (2009). However, the designer can add as many terms as necessary to Equation 1to consider other ergonomic criteria.

\section{Experimental application}

To verify the operation of the proposed system an experiment was performed in an assembly workstation of a toy factory. In this post, small parts and sub-assemblies are assembled using different types of tools. All needed parts and required tools were distributed in a workbench. The assembly sequence was fixed, and the operations were always carried out in the same order. Fig. 5a illustrates the initial layout of the items in the work area.

The workstation was observed over several work cycles. The average assembly cycle time was $380.2 \mathrm{~s}$ with small deviations of a few seconds in some cycles. Item distribution and their required areas were analyzed and minimum and maximum geometric ratios were determined. Plant engineers were consulted to set the maximum and minimum ratios. In addition, it was determined which items should be placed on the left or right of the worker because they had to be employed or reached preferably with one of his hands. The analysis provided a list of 20 items to be distributed (identified with numbers from 1 to 20) whose characteristics are described in Table 1 . Work area dimensions were $\mathrm{W}=157.0$ and $\mathrm{H}=73.1 \mathrm{~cm}$.

The second column of Table 1 indicates the area of each item. The next three columns show the minimum and maximum ratios of each item and the ratio in the initial layout of the workstation. The sixth column shows the side where the item should preferably be located. The eighth and ninth columns indicate whether the handled object was heavy and if it required precision or careful handling. Asterisks in the third column of Table 1 indicate if the item was considered as having free orientation. An item meets its geometric constraints when its ratio lies in the range between the minimum and maximum ratio. In the case of a free orientation item the symmetric interval relative to 1 , that is $\left[1 / r_{\max }, 1 / r_{\min }\right]$, is also considered valid. For example, in the case of item 3 the validity ratio was $[0.50,0.80]$. As it is a free orientation item the ratios in the range $[1.25,2.00]$ were also considered valid.

A Kinect sensor and a desktop PC with a $3.6 \mathrm{GHz}$ processor and 12 GB RAM were used to analyze 10 consecutive work cycles (Fig. 3). After some tests, the height of all VS (h) was set at $35 \mathrm{~cm}$ and $\mathbf{t}_{\mathbf{h}}$ was set at $0.3 \mathrm{~s}$. Since the assembly order was fixed, the sequence of activation of the VS was equal in all work cycles with only some small differences in their activation times. Therefore, instead of using the data of 10 cycles, only one cycle with the mean activation times of 10 cycles was analyzed. VS activation sequence and mean activation times are shown in Fig. 4. The number of times that each VS was activated is shown in the seventh column of Table 1.

As it has been aforementioned in Section 4.3, the fitness function of the GA must be adapted to the characteristics of the workstation and the developed task. In this case, two terms were added to Equation (1) to consider two ergonomic criteria, giving place to Equation (2), which was used as fitness function. In addition to the Relational Cost and Geometrical Cost of Equation (1), Equation (2) includes two additional terms.

The third term of Equation (2) was called Positional Cost. When a workstation is analyzed the evaluator must state the suitable side for each item. If an object is usually reached or used with the right hand, it is convenient to place this item in the right side of the worker. In this term, $\mathbf{d}_{\mathbf{i}}$ depends on the distance from the center of item $\mathbf{i}$ to an axis that divides the working plane into two equal halves, left and right ( $E$ in Fig. 5). $\mathbf{d}_{\mathbf{i}}$ takes the value 0 if the center of 
Table 1

Characteristics of the items to be distributed in the case study. Asterisks in the third column indicate if the item was considered as having free orientation.

\begin{tabular}{|c|c|c|c|c|c|c|c|c|c|}
\hline \multirow[t]{2}{*}{ Item ID } & \multirow[t]{2}{*}{ Area $\left(\mathrm{m}^{2}\right)$} & \multicolumn{3}{|l|}{ Ratio } & \multirow[t]{2}{*}{ Preferred side } & \multirow[t]{2}{*}{ Access count } & \multirow{2}{*}{$\begin{array}{l}\text { Heavy } \\
\text { item }\end{array}$} & \multirow[t]{2}{*}{ Precision required } & \multirow[t]{2}{*}{$r_{1 j}$} \\
\hline & & initial & $\min$ & $\max$ & & & & & \\
\hline 1 & 0.1476 & 0.65 & 0.40 & 0.8 & center & 1 & No & No & - \\
\hline 2 & 0.0682 & 1.41 & 0.60 & 1.66 & right & 2 & No & No & 0.4 \\
\hline 3 & 0.1342 & $1.38^{*}$ & 0.50 & 0.80 & left & 2 & No & No & 0.8 \\
\hline 4 & 0.0517 & 1.07 & 0.33 & 1.23 & right & 3 & No & No & 0.8 \\
\hline 5 & 0.0359 & 0.37 & 0.33 & 0.66 & indifferent & 2 & No & Yes & 1.6 \\
\hline 6 & 0.0799 & $0.69^{*}$ & 0.57 & 0.75 & indifferent & 3 & No & No & 0.8 \\
\hline 7 & 0.0320 & 1.73 & 0.50 & 2.00 & right & 5 & No & Yes & 1.6 \\
\hline 8 & 0.0341 & 0.70 & 0.57 & 1.72 & right & 1 & Yes & Yes & 2.6 \\
\hline 9 & 0.0341 & $0.70^{*}$ & 0.57 & 1.72 & indifferent & 4 & No & No & 0.4 \\
\hline 10 & 0.0343 & $0.71^{*}$ & 0.50 & 0.80 & left & 4 & Yes & No & 2.2 \\
\hline 11 & 0.0341 & $0.70^{*}$ & 0.57 & 0.92 & right & 2 & No & No & 2.0 \\
\hline 12 & 0.0378 & $2.54^{*}$ & 0.30 & 0.75 & indifferent & 3 & No & No & 0.8 \\
\hline 13 & 0.0260 & $0.54^{*}$ & 0.42 & 0.75 & indifferent & 1 & No & Yes & 1.6 \\
\hline 14 & 0.0804 & 0.69 & 0.57 & 0.92 & right & 1 & No & No & 0.4 \\
\hline 15 & 0.0664 & $1.37^{*}$ & 0.42 & 0.92 & indifferent & 4 & No & No & 0.4 \\
\hline 16 & 0.0216 & $1.60^{*}$ & 0.32 & 0.75 & left & 5 & No & No & 1.6 \\
\hline 17 & 0.0335 & 1.03 & 0.80 & 1.25 & right & 2 & No & No & 2.0 \\
\hline 18 & 0.0577 & $0.60^{*}$ & 0.50 & 0.80 & right & 2 & No & Yes & 1.2 \\
\hline 19 & 0.0815 & $0.42^{*}$ & 0.37 & 0.90 & right & 1 & No & No & 0.8 \\
\hline 20 & 0.0569 & 0.61 & 0.50 & 1.94 & left & 1 & No & No & 0.4 \\
\hline
\end{tabular}

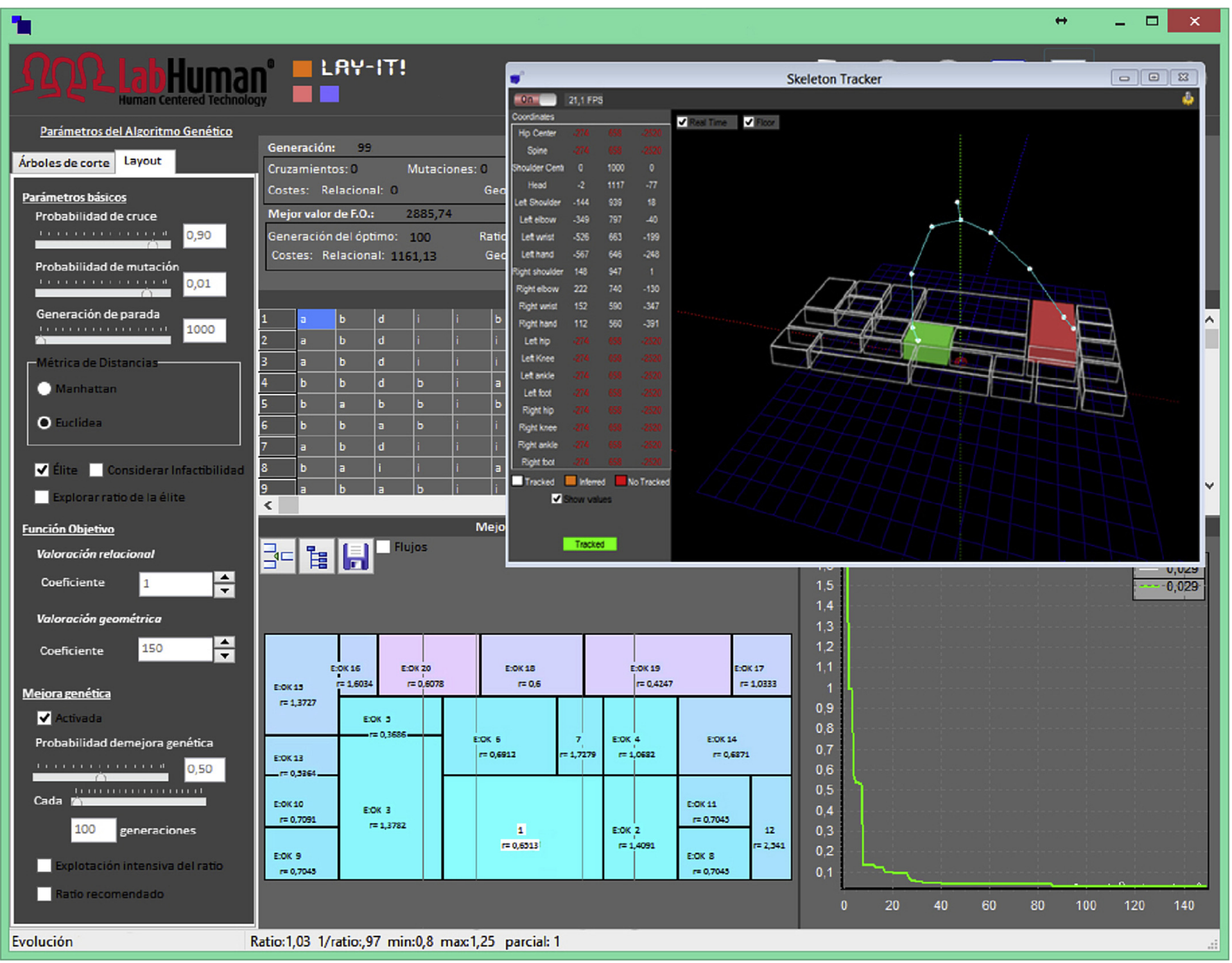

Fig. 3. Right and left hands activating two virtual sensors in the tracking module. 


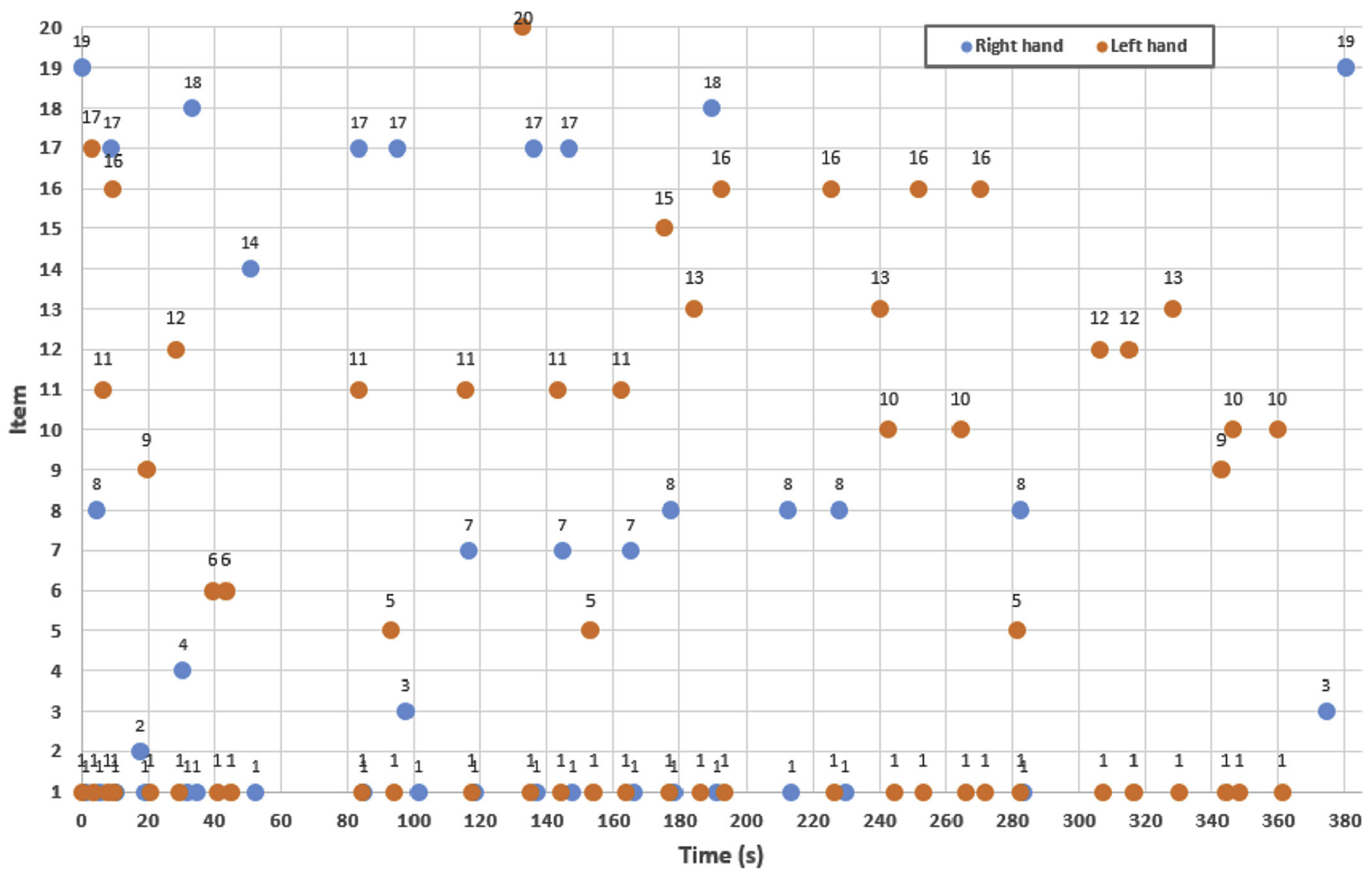

Fig. 4. VS activation sequence and mean activation times.

item $\mathbf{i}$ is placed on the preferred side of the axis (Table 1 ). Otherwise, $\mathbf{d}_{\mathbf{i}}$ takes the value of the distance from the center of item $\mathbf{i}$ to the axis. Thus, layouts where items are placed on the preferred side have a lower Positional Cost. More the layout breaches these conditions, the more the Positional Cost increases. If a layout accomplish all the positional conditions, the Positional Cost becomes 0 .

The fourth term of Equation (2) was called Fixed Cost. Sometimes some items should be located at specific positions in the layout. For example, in this case, item 1 was the area that the worker used for assembly operations. The worker reached pieces and tools from other items and conducted operations in the area defined by item 1 . For this reason, the item 1 should be located opposite the worker. For this end, Fixed Cost was added to Equation (2). In this term $\mathbf{d p}_{\mathbf{1}}$ takes the value 0 if the center of item 1 is on the $\mathrm{E}$ axis and one side coincides with the edge of the working area. Otherwise $\mathbf{d p}_{\mathbf{1}}$ takes value 1 .

Finally, heavy objects and precision handling were also considered in the analysis (Table 1). To this purpose, Equation (3) was used to calculate each $\mathbf{r}_{\mathbf{i j}}$. In this equation, $\mathbf{A c c}_{\mathbf{i j}}$ is the number of times the hands moved from item $\mathbf{i}$ to $\mathbf{j}$ or from $\mathbf{j}$ to $\mathbf{i}$. $\mathbf{H}_{\mathbf{i j}}$ takes value 1 for heavy objects and 0 otherwise, $\mathbf{P}_{\mathbf{i j}}$ takes the same values depending on whether the item demands precision handling, and $\mathbf{C a}, \mathbf{C w}$ and $\mathbf{C p}$ are weighting coefficients. In this case study they were assigned values $0.4,0.2$ and 0.4 respectively. The items handled in the workstation were not too heavy, therefore it was considered convenient to assign a lower value to Cw. All movements began or ended in item 1 (the assembly area in front of the operator), therefore, $\mathbf{r}_{\mathbf{i j}}$ took the value 0 except when $\mathbf{i}$ or $\mathbf{j}$ were equal to 1 . These values are shown in the last column of Table 1. Coefficients $\mathbf{C r}, \mathbf{C g}$, Cs and $\mathbf{C 1}$ of Equation (2) were assigned values 1,
150,10 and 200, respectively. The values of these coefficients were set according to the range of absolute values of each cost and their relative importance.

$$
\begin{aligned}
& C=C r \sum_{i=1}^{n} \sum_{j=1}^{n} d_{i j} r_{i j}+C g \sum_{i=1}^{n} i g_{i}+C s \sum_{i=1}^{n} d_{i}+C 1 d p_{1} \\
& r_{i j}=C a \cdot A c c_{i j}+C w \cdot H i j+C p P_{i j}
\end{aligned}
$$

\subsection{Sensitivity of the procedure to parameters variations}

In the presented procedure, the $\mathbf{t}_{\mathbf{h}}$ parameter and the height (h) of the VS must be defined by the evaluator. If $\mathbf{t}_{\mathbf{h}}$ value is too small, false positives could occur when the hand crosses others VS to reach the target VS. On the other hand, if the value is too big, the access to some items could not be detected. By definition, the $\mathbf{h}$ value in each VS must be greater than the height of the VS. In our experimental application the same value $(35 \mathrm{~cm})$ was used. This value was $15 \mathrm{~cm}$ greater than the height of the higher item. In order to establish the robustness of this procedure to the variations of $\mathbf{t}_{\mathbf{h}}$ and $\mathbf{h}$, the values of these parameters were varied and the VS activation sequence was recalculated for each combination of parameters.

$\mathbf{t}_{\mathbf{h}}$ was varied between 0.1 and $1.0 \mathrm{~s}$ with increments of $0.1 \mathrm{~s}$. For each of these values of $\mathbf{t}_{\mathbf{h}}$, $\mathbf{h}$ took the values $20,25,30,35,40,45$ and $50 \mathrm{~cm}$. The solution obtained by the GA depends only on the VS activation sequence, therefore, if there is not changes in the activation sequence there will not be changes in the final solution. The 
a)

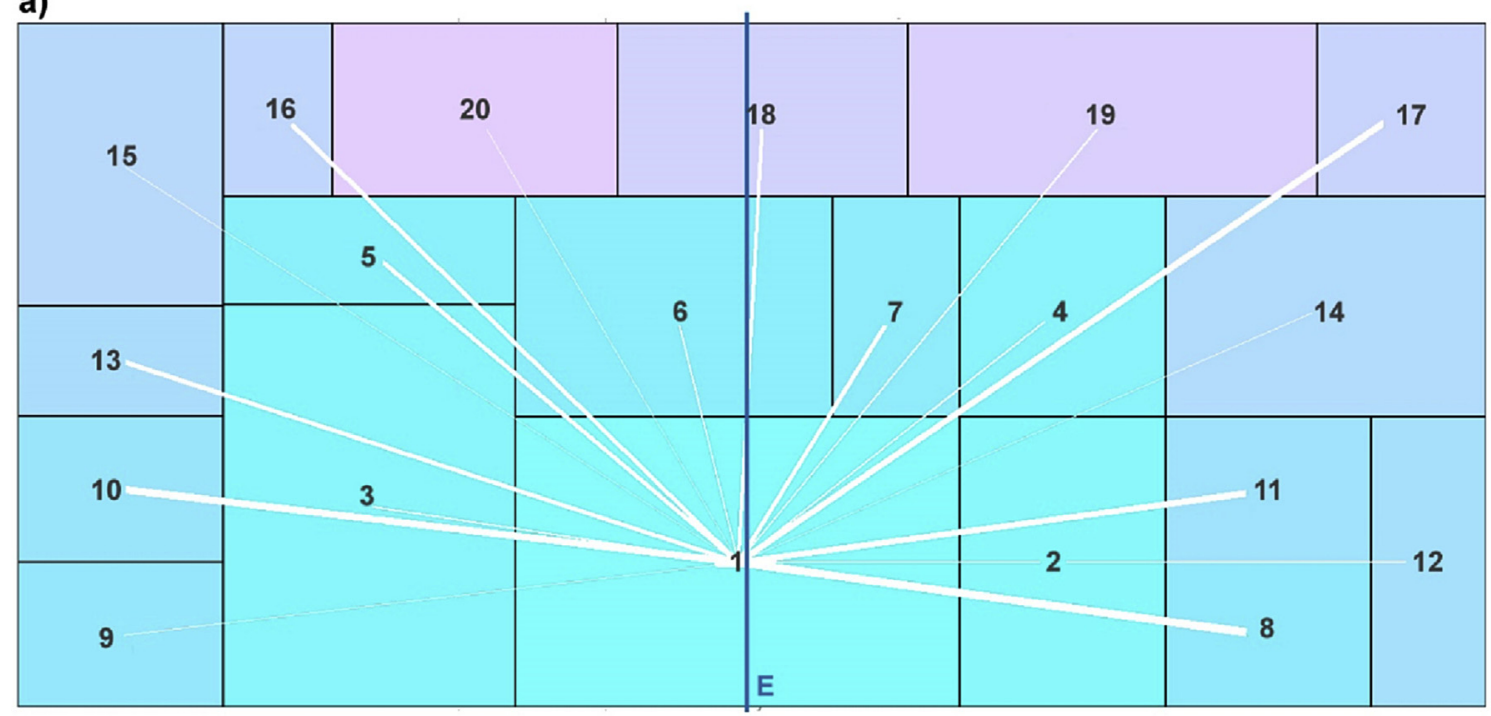

b)

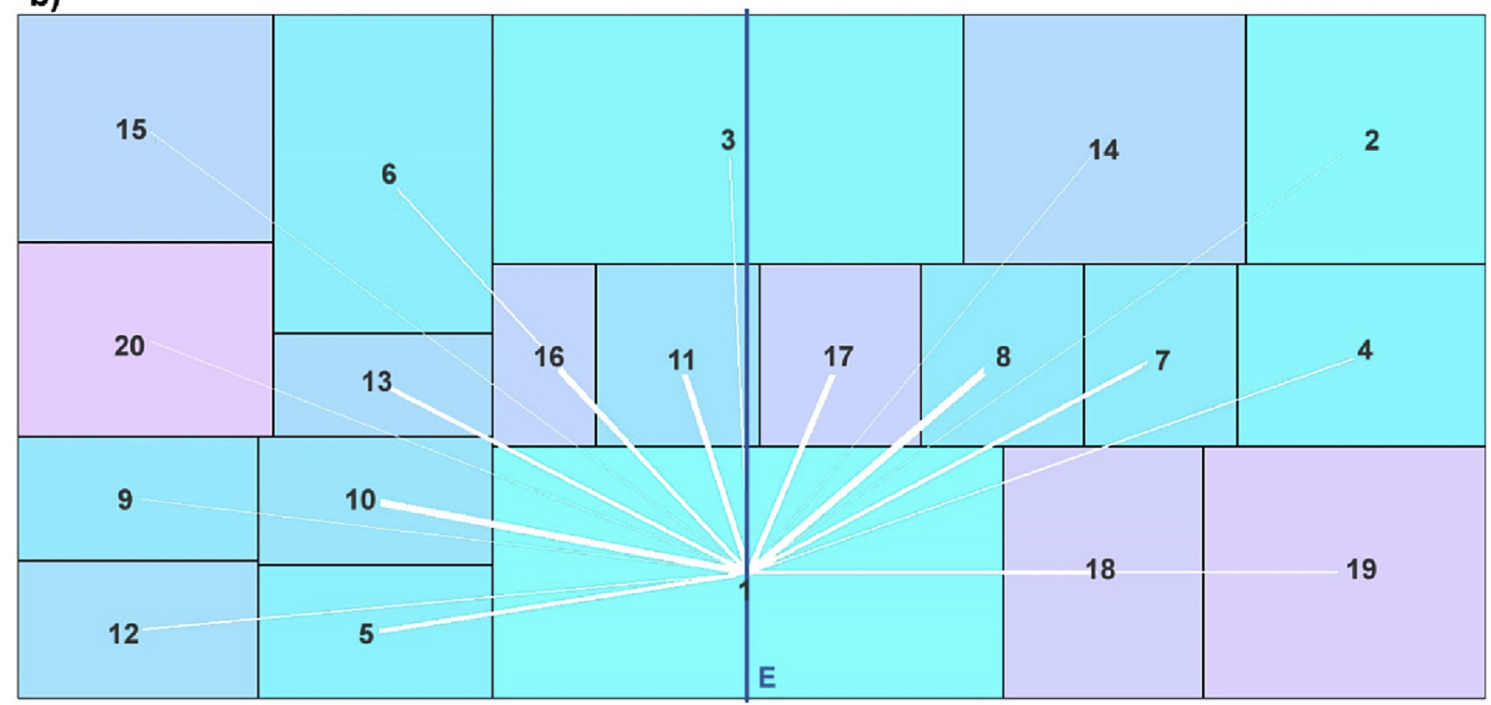

Fig. 5. Initial (a) and optimized (b) workstation layout. Thickness of white lines is proportional to the relationships between the linked areas.

worker activity during the task development was captured using Kinect Studio 2.0. Then, it was not necessary to capture the data again for each combination of parameters.

\section{Results}

The GA used in this work was a genetic algorithm in two stages (Diego-Mas et al., 2009). Both stages were executed for 1000 generations. The probabilities of crossover and mutation were set at 0.9 and 0.01 respectively, and the population size was 50 . The time taken by the calculation module on a desktop PC with a $3.6 \mathrm{GHz}$ processor and 12 GB RAM was 4 min and $20 \mathrm{~s}$.

The best workstation layout generated by the GA is shown in Fig. 5b. The cost of this layout, calculated with Equation (2), is 977.51. In this solution all items are located on the preferred side to facilitate access with the correct worker's hand, and geometric constraints of all items are met. Item 1 is located opposite the position of the worker. Thus, Geometrical, Positional and Fixed costs of the GA solution are 0 , so that the overall cost of the solution is due to the Relational Cost.
The thickness of the white lines in Fig. 5 is proportional to the level of relationship of the activities that these lines connect. The items joined by thicker lines require more closeness. In the workstation layout generated by the GA, the length of the thicker lines is lower than in the initial layout. The Relational Cost of the initial layout was 1315.65; therefore, the GA solution achieved a reduction of $25.76 \%$. The Positional Cost of the GA solution is 0 , while in the initial layout some items were placed on the wrong side.

\subsection{Results of the sensitivity analyses}

Two kind of errors could be make when $\mathbf{t}_{\mathbf{h}}$ and $\mathbf{h}$ values are improperly set: missing the access to an VS that the hand of the worker really reaches (Missing VS accesses in Table 2) and detecting the access to a VS when the hand crosses others VS to reach the target VS (False positives in Table 2). Table 2 presents the number of each kind of error for each combination of parameters. The number of errors was calculated comparing each obtained sequence with the original sequence. The original sequence had been previously checked to ensure that it was free of errors. The only $\mathbf{h}$ value that 
Table 2

Results of the sensitivity analysis.

\begin{tabular}{llll}
\hline $\mathbf{t}_{\mathrm{h}}$ value (s.) & h value $(\mathrm{cm})$. & Missing VS accesses & False positives \\
\hline $\mathbf{0 . 1}$ & 20 & 1 & 4 \\
& Rest of values & 0 & 4 \\
$\mathbf{0 . 2}$ & 20 & 1 & 1 \\
& Rest of values & 0 & 1 \\
$\mathbf{0 . 3}$ & 20 & 1 & 0 \\
& Rest of values & 0 & 0 \\
$\mathbf{0 . 4}$ & 20 & 1 & 0 \\
& Rest of values & 0 & 0 \\
$\mathbf{0 . 5}$ & 20 & 1 & 0 \\
& Rest of values & 0 & 0 \\
$\mathbf{0 . 6}$ & 20 & 1 & 0 \\
& Rest of values & 0 & 0 \\
$\mathbf{0 . 7}$ & 20 & 2 & 0 \\
& Rest of values & 1 & 0 \\
$\mathbf{0 . 8}$ & 20 & 4 & 0 \\
& Rest of values & 3 & 0 \\
$\mathbf{0 . 9}$ & 20 & 5 & 0 \\
\multirow{2}{*}{$\mathbf{1 . 0}$} & Rest of values & 4 & 0 \\
& 20 & 7 & 0 \\
& Rest of values & 6 & 0 \\
\hline
\end{tabular}

changes the activation sequence is $20 \mathrm{~cm}$. For this reason, the results are grouped in two intervals for $\mathbf{h}$ value $(20 \mathrm{~cm}$ and Rest of values).

\section{Discussion}

The use of RGB-D sensors as 3D motion capture systems in the field of ergonomics is promising. The tracking algorithms of these devices automatically record body positions at high sampling frequency without the disadvantages of other systems based on markers placed on the skin or inertial sensors (cost, setup times, skilled technical staff, discomfort) (Clark et al., 2012). However, this technology should be further developed to be used widely in real working environments. It is necessary to solve certain problems like the position of the worker facing the sensor or lack of accuracy when a body part is hidden by an object or another part of the body. Recent studies try to solve these problems through the simultaneous use of several sensors placed in different sites (Asteriadis et al., 2013; Berger et al., 2013; Geiselhart et al., 2016; Zhang et al., 2012). However, the use of several sensors must deal with problems such as interference in the speckle patterns projected onto the scene or differences in the positions of the tracked joints of each sensor (Sarbolandi et al., 2015). Moreover, the accuracy of the lower body data is poor (Yang et al., 2015), and joint rotations are not correctly captured or not captured at all for the peripheral limbs or the head.

In this paper we have used data from RGB-D sensors for the optimization of the layout of working elements in workstations. In this proposal, current limitations of RGB-D sensors and tracking algorithms have been taken into account. The level of development of the sensors is enough to automate this process since only data from the upper limbs are needed, the work area is limited and the sensor can be placed conveniently relative to the worker. The presented system combines the data obtained by the sensor with genetic algorithms for solving the FLP problem. This model can generate workstation layouts adapted simultaneously to several workers or to various production processes in the same post. In addition, the system can automatically generate new layouts when the workers' sequence of movements change and, since tracking algorithms can capture several workers simultaneously, it could be adapted for designing workstations for group interaction (Mahoney et al., 2015).
Different kinds of sensors could be used to detect the positions of the hands (motion capture systems, inertial sensors, presence detectors placed in the working area ...). These devices are able to detect the hand's positions more accurately than RGB-D sensors. However, accuracy is not a big advantage in this application because it only need to detect if the hands are inside or outside the virtual sensors. Using RGB-D sensors are less invasive, cheaper and do not require complex calibration processes. Therefore, although other methods can be preferred for research purposes, RGB-D sensors are suitable for use in real work situations where portability, usability and low cost are critical.

Optimizing the arrangement of the working elements should take productive and ergonomic criteria into consideration. There are many ergonomic criteria so that their selection depends on the type of task and objectives. The proposed system is flexible as it allows designers to consider as many criteria as necessary. The GA used to optimize workstation layout employs a cost function (Equation (2)) that can be modified by introducing new terms to consider other criteria. For example, in this paper we have only considered the position of the worker's hands. Although for the purpose of the present study this information is sufficient, it might be interesting to track the position of other body joints. For example, if the position of the shoulders and elbows is tracked during the development of the task, the abduction angle of the arms could be calculated and used as criterium.

The tests have revealed certain limitations in the system. For example, handling large objects can prevent the correct detection of hand position. Therefore, the procedure described is suitable for small parts assembly workstations. In the case study, the worker was handling small parts and tools, so this problem did not occur. However, when testing with larger items, in some cases the hand positions were inferred or not tracked. Although in these test the accuracy of the inferred positions was sufficient to activate the correct VS, this can be a problem if the size of the VS is small. Similarly, when the worker's hands are close to the work plane the number of inferred positions increases. This occurs mainly when the angle between the line of sight of the sensor and the working plane is very large (sensor placed very high relative to the work plane) or when the sensor is too close to the working plane. When the working plane is horizontal or close to horizontal, this problem can be solved with proper placement of the RGB-D sensor and a suitable definition of $\mathbf{t}_{\mathbf{h}}$. However, when the angle of the working plane with the horizontal is large it can be difficult to find a suitable position for the sensor.

RGB-D sensors have non-ignorable measurement errors. To deal with this problem, some parameters of the presented procedure $\left(\mathbf{t}_{\mathbf{h}}\right.$ and $\mathbf{h}$ ) must be correctly set by the evaluator. In order to measure the robustness of this method when these parameters change, a sensitivity analysis was performed. $\mathbf{t}_{\mathbf{h}}$ and $\mathbf{h}$ were varied in the intervals $[0.1,1.0]$ seconds and $[20,50]$ centimeters respectively, and the number of missing real VS accesses and false positives were measured. In Table 2 can be seen that the number of false positives increases when $\mathbf{t}_{\mathbf{h}}$ is lower than 0.3 , and the number of missing VS accesses increases when $\mathbf{t}_{\mathbf{h}}$ is over 0.6. However, the activation sequence does not vary when the $\mathbf{t}_{\mathbf{h}}$ value ranges between 0.3 and $0.6 \mathrm{~s}$, except when the $\mathbf{h}$ value is $20 \mathrm{~cm}$. In this regard, it seems that the $\mathbf{h}$ value does not influence the activation sequence except when its value is too low. In the workstation used in our experimental application the height of the higher item was $20 \mathrm{~cm}$. When $\mathbf{h}$ is set to $20 \mathrm{~cm}$ the VS corresponding to this item has the same height than the item, avoiding that the hand can be properly detected. In Table 2 could be seen that, when $\mathbf{h}$ is $20 \mathrm{~cm}$, there is always one more missing VS access than when $\mathbf{h}$ is bigger. In all the cases, this added missing VS access corresponds to the higher item of the workstation. 
Considering the limitations of our experimental application, it seems that this procedure has enough robustness when the parameters change. The evaluator should take the precaution of setting $\mathbf{h}$ value at least $5 \mathrm{~cm}$ bigger than the actual item. On the other hand, although setting $\mathbf{t}_{\mathbf{h}}$ value requires some previous test, the interval of values that produces good results is wide enough, and it is not critical to set some specific value.

Another limitation of our work is related with the real ergonomic performance of the solutions obtained using this procedure. In the proposed method, the fitness function used in the GA guides the search for the best layout. Therefore, to consider correctly the necessary ergonomic criteria in the fitness function is crucial. If the fitness function is correctly defined the probability of obtaining a good ergonomic performance in the found layout is high, however, it is necessary to ensure this through a real ergonomic postassessment. In this regard, our future research will be focused on measuring the ergonomic quality of the solutions obtained using this algorithm, and how the definition of the fitness function of the GA, and its weighting coefficients, affects the ergonomics of the workstation. Meanwhile, a human expert must validate the solution obtained before putting it into practice. In its current form, this procedure is a tool to support the tasks of the ergonomists, but human experts must take the final decision.

Other future work may try to extend the capacity of the system to workstations with several working planes in different orientations. Achieving this objective implies to adapt the GA in order to distribute the items in different working surfaces.

\section{Conclusions}

Although RGB-D sensor technology should be further developed so that its use is widespread in real work environments, nowadays it is possible to use them in applications that take into account their current limitations. In this paper a RGB-D sensor has been used for acquire body postural data which were further processed by a genetic algorithm to optimize workstation layout. The results show that this application allows automating and simplifying this process. The system can generate layouts adapted to several production processes for workstations where several products are manufactured, or layouts optimized for several workers that occupy the same workstations in different shifts.

\section{Acknowledgements}

This work was supported by the Programa estatal de investigación, desarrollo e innovación orientada a los retos de la sociedad of the Government of Spain under Grant TIN2013-42504-R.

\section{References}

Amaral, A.R.S., 2006. On the exact solution of a facility layout problem. Eur. J. Oper. Res. 173, 508-518. http://dx.doi.org/10.1016/j.ejor.2004.12.021.

Asteriadis, S., Chatzitofis, A., Zarpalas, D., Alexiadis, D.S., Daras, P., 2013. Estimating human motion from multiple Kinect sensors. In: Proceedings of the 6th International Conference on Computer Vision/Computer Graphics Collaboration Techniques and Applications. MIRAGE '13, p. 1. http://dx.doi.org/10.1145/ 2466715.2466727.

Battini, D., Faccio, M., Persona, A., Sgarbossa, F., 2011. New methodological framework to improve productivity and ergonomics in assembly system design. Int. J. Ind. Ergon. 41, 30-42. http://dx.doi.org/10.1016/j.ergon.2010.12.001.

Berger, K., Meister, S., Nair, R., Kondermann, D., 2013. A state of the art report on research in multiple RGB-D sensor setups. In: Grzegorzek, M., Theobalt, C., Koch, R., Kolb, A. (Eds.), Time-of-Flight and Depth Imaging. Sensors, Algorithms, and Applications. Springer-Verlag Berlin Heidelberg, Berlin, pp. 257-272. http://dx.doi.org/10.1007/978-3-642-44964-2_12.

Best, R., Begg, R., 2006. Overview of movement analysis and gait features. Libr. Google Play Comput. Intell. Mov. Sci. Neutral Netw. Other Emerg. Tech 1-69. http://dx.doi.org/10.4018/978-1-59140-836-9.

Bonnechère, B., Jansen, B., Salvia, P., Bouzahouene, H., Omelina, L., Moiseev, F.,
Sholukha, V., Cornelis, J., Rooze, M., Jan, S.V.S., 2013a. Validity and reliability of the Kinect within functional assessment activities: comparison with standard stereophotogrammetry. Gait Posture. http://dx.doi.org/10.1016/ j.gaitpost.2013.09.018.

Bonnechère, B., Sholukha, V., Moiseev, F., Rooze, M., S, V.S.J., 2013b. From KinectTM to anatomically-correct motion modelling: preliminary results for human application. In: Schouten, B., Fedtke, S., Bekker, T., Schijven, M., Gekker, A. (Eds.), Games for Health: Proceedings of the 3rd European Conference on Gaming and Playful Interaction in Health Care. Springer Fachmedien Wiesbaden, Wiesbaden, pp. 15-24. http://dx.doi.org/10.1007/978-3-658-02897-8.

Brodie, M.A., Walmsley, A., Page, W., 2008. The static accuracy and calibration of inertial measurement units for 3D orientation. Comput. Methods Biomech. Biomed. Engin 11, 641-648. http://dx.doi.org/10.1080/10255840802326736.

Clark, R. a, Pua, Y.-H., Fortin, K., Ritchie, C., Webster, K.E., Denehy, L., Bryant, A.L., 2012. Validity of the Microsoft Kinect for assessment of postural control. Gait Posture 36, 372-377. http://dx.doi.org/10.1016/j.gaitpost.2012.03.033.

Clark, R.A., Bower, K.J., Mentiplay, B.F., Paterson, K., Pua, Y.H., 2013. Concurrent validity of the Microsoft Kinect for assessment of spatiotemporal gait variables. J. Biomech. 46, 2722-2725. http://dx.doi.org/10.1016/j.jbiomech.2013.08.011.

Das, B., Behara, D.N., 1995. Determination of the normal horizontal working area: a new model and method. Ergonomics 38, 734-748. http://dx.doi.org/10.1080/ 00140139508925145.

Das, B., Sengupta, A.K., 1996. Industrial workstation design: a systematic ergonomics approach. Appl. Ergon. 27, 157-163. http://dx.doi.org/10.1016/00036870(96)00008-7.

Deros, B.M., Khamis, N.K., Ismail, A.R., Jamaluddin, H., Adam, A.M., Rosli, S., 2011. An Ergonomics study on assembly line workstation design. Am. J. Appl. Sci. 8, 1195-1201. http://dx.doi.org/10.3844/ajassp.2011.1195.1201.

Destelle, F., Ahmadi, A., O'Connor, N.E., Moran, K., Chatzitofis, A., Zarpalas, D., Daras, P., 2014. Low-cost accurate skeleton tracking based on fusion of kinect and wearable inertial sensors. In: European Signal Processing Conference, pp. 371-375.

Diego-Mas, J.A., Alcaide-Marzal, J., 2014. Using Kinect ${ }^{\mathrm{TM}}$ sensor in observational methods for assessing postures at work. Appl. Ergon. 45, 976-985. http:// dx.doi.org/10.1016/j.apergo.2013.12.001.

Diego-Mas, J.A., Santamarina-Siurana, M.C., Cloquell-Ballester, V.A., AlcaideMarzal, J., 2008. Slicing tree's geometric potential: an indicator for layout problems based on slicing tree structure. Int. J. Prod. Res. 46, 1071-1087. http:// dx.doi.org/10.1080/00207540600932061.

Diego-Mas, J.A., Santamarina-Siurana, M.C., Alcaide-Marzal, J., CloquellBallester, V.A., 2009. Solving facility layout problems with strict geometric constraints using a two-phase genetic algorithm. Int. J. Prod. Res. 47, 1679-1693,. http://dx.doi.org/10.1080/00207540701666253.

Drira, A., Pierreval, H., Hajri-Gabouj, S., 2007. Facility layout problems: a survey. Annu. Rev. Control 31, 255-267. http://dx.doi.org/10.1016/ j.arcontrol.2007.04.001.

Dutta, T., 2012. Evaluation of the Kinect ${ }^{\mathrm{TM}}$ sensor for 3-D kinematic measurement in the workplace. Appl. Ergon. 43, 645-649. http://dx.doi.org/10.1016/ j.apergo.2011.09.011.

Dyckhoff, H., 1990. A typology of cutting and packing problems. Eur. J. Oper. Res. 44, 145-159. http://dx.doi.org/10.1016/0377-2217(90)90350-K.

El-Baz, M.A., 2004. A genetic algorithm for facility layout problems of different manufacturing environments. Comput. Ind. Eng. 47, 233-246. http://dx.doi.org/ 10.1016/j.cie.2004.07.001.

Fernández-Baena, A., Susín, A., Lligadas, X., 2012. Biomechanical validation of upper-body and lower-body joint movements of kinect motion capture data for rehabilitation treatments. In: Proceedings of the 2012 4th International Conference on Intelligent Networking and Collaborative Systems, vol. 2012. INCoS, pp. 656-661. http://dx.doi.org/10.1109/iNCoS.2012.66.

Garcia, J., Zalevsky, Z., 2007. Range Mapping Using Speckle Decorrelation. Google Patents. US 20070216894 A1.

Geiselhart, F., Otto, M., Rukzio, E., 2016. On the use of multi-depth-camera based motion tracking systems in production planning environments. Procedia CIRP 41, 759-764. http://dx.doi.org/10.1016/j.procir.2015.12.088.

Goldberg, D.E., 1989. Genetic Algorithms in Search, Optimization and Machine Learning. Addison-Wesley Longman Publishing Co., Inc, Boston, MA.

Haggag, H., Hossny, M., Nahavandi, S., Creighton, D., 2013. Real time ergonomic assessment for assembly operations using kinect. In: Proceedings - UKSim 15th International Conference on Computer Modelling and Simulation, vol. 2013. UKSim, pp. 495-500. http://dx.doi.org/10.1109/UKSim.2013.105.

Han, J., Shao, L., Xu, D., Shotton, J., 2013. Enhanced computer vision with Microsoft Kinect sensor: a review. IEEE Trans. Cybern. 43, 1318-1334. http://dx.doi.org/ 10.1109/TCYB.2013.2265378.

Hani, Y., Amodeo, L., Yalaoui, F., Chen, H., 2007. Ant colony optimization for solving an industrial layout problem. Eur. J. Oper. Res. 183, 633-642. http://dx.doi.org/ 10.1016/j.ejor.2006.10.032.

Hasegawa, M., Ikeguchi, T., Aihara, K., Itoh, K., 2002. A novel chaotic search for quadratic assignment problems. Eur. J. Oper. Res. 139, 543-556. http:// dx.doi.org/10.1016/S0377-2217(01)00189-8.

Henry, P., Krainin, M., Herbst, E., Ren, X., Fox, D., 2012. RGB-D mapping: using Kinect-style depth cameras for dense 3D modeling of indoor environments. Int. J. Rob. Res. 31, 647-663. http://dx.doi.org/10.1177/0278364911434148.

Islier, A.A., 1998. A genetic algorithm approach for multiple criteria facility layout design. Int. J. Prod. Res. 36, 1549-1569. http://dx.doi.org/10.1080/ 002075498193165. 
Jain, P.K., Sharma, P.K., 2005. Solving job shop layout problem using ant colony optimization technique. Man and Cybernetics. In: 2005 IEEE International Conference on Systems, pp. 288-292. http://dx.doi.org/10.1109/ ICSMC.2005.1571160.

James, T., Rego, C., Glover, F., 2009. Multistart tabu search and diversification strategies for the quadratic assignment problem. IEEE Trans. Syst. Man. Cybern. Part ASystems Hum. 39, 579-596. http://dx.doi.org/10.1109/TSMCA.2009.2014556.

Khoshelham, K., Elberink, S., 2012. Accuracy and resolution of kinect depth data for indoor mapping applications. Sensors 12, 1437-1454. http://dx.doi.org/ $10.3390 /$ s120201437.

Kusiak, A., Heragu, S.S., 1987. The facility layout problem. Eur. J. Oper. Res. http:// dx.doi.org/10.1016/0377-2217(87)90238-4.

Mahoney, J.M., Kurczewski, N.A., Froede, E.W., 2015. Design method for multi-user workstations utilizing anthropometry and preference data. Appl. Ergon. 46, 60-66. http://dx.doi.org/10.1016/j.apergo.2014.07.003.

Merz, P., Freisleben, B., 1999. A comparison of memetic algorithms, tabu search, and ant colonies for the quadratic assignment problem. Cat No 99TH8406 Proc. 1999 Congr. Evol. Comput. 3, 2063-2070. http://dx.doi.org/10.1109/CEC.1999.785529.

Nixon, M.E., Howard, A.M., Chen, Y.P., 2013. Quantitative evaluation of the Microsoft KinectTM for use in an upper extremity virtual rehabilitation environment. In: 2013 International Conference on Virtual Rehabilitation, vol. 2013. ICVR, pp. 222-228. http://dx.doi.org/10.1109/ICVR.2013.6662131.

NUI, 2013. Natural user interface for kinect for windows [WWW document] Microsoft Dev. Netw. http://msdn.microsoft.com/en-us/library/hh855352.aspx.

Obdrzálek, S., Kurillo, G., Ofli, F., Bajcsy, R., Seto, E., Jimison, H., Pavel, M., 2012. Accuracy and robustness of Kinect pose estimation in the context of coaching of elderly population. Conf. Proc. IEEE Eng. Med. Biol. Soc. 2012, 1188-1193. http:// dx.doi.org/10.1109/EMBC.2012.6346149.

Occupational Outlook Handbook, 2015 [WWW Document] Bur. Labor Stat. U.S. Dep. Labor. http://www.bls.gov/ooh/production/assemblers-and-fabricators.htm (accessed 5.30.16)

Önüt, S., Tuzkaya, U.R., Doğaç, B., 2008. A particle swarm optimization algorithm for the multiple-level warehouse layout design problem. Comput. Ind. Eng. 54, 783-799. http://dx.doi.org/10.1016/j.cie.2007.10.012.

Patrizi, A., Pennestrì, E., Valentini, P.P., 2015. Comparison between low-cost markerless and high-end marker-based motion capture systems for the computeraided assessment of working ergonomics. Ergonomics 1-11. http://dx.doi.org/ 10.1080/00140139.2015.1057238.

Pfister, A., West, A.M., Bronner, S., Noah, J.A., 2014. Comparative abilities of Microsoft Kinect and Vicon 3D motion capture for gait analysis. J. Med. Eng. Technol. 38, 274-280. http://dx.doi.org/10.3109/03091902.2014.909540.

Plantard, P., Auvinet, E., Pierres, A.-S., Le, Multon, F., 2015. Pose estimation with a Kinect for ergonomic studies: evaluation of the accuracy using a virtual mannequin. Sens. (Basel) 15, 1785-1803. http://dx.doi.org/10.3390/s150101785.

Saifullah Hussin, M., Stützle, T., 2014. Tabu search vs. simulated annealing as a function of the size of quadratic assignment problem instances. Comput. Oper. Res. 43, 286-291. http://dx.doi.org/10.1016/j.cor.2013.10.007.

Sanders, M.S., McCormick, E.J., 1993. Human Factors in Engineering and Design. McGraw-Hill, New York.
Santos, J., Sarriegi, J.M., Serrano, N., Torres, J.M., 2007. Using ergonomic software in non-repetitive manufacturing processes: a case study. Int. J. Ind. Ergon. 37, 267-275. http://dx.doi.org/10.1016/j.ergon.2006.10.022.

Saptari, A., Lai, W.S., Salleh, M.R., 2011. Jig design, assembly line design and work station design and their effect to productivity. Jordan J. Mech. Ind. Eng. 5, 9-16.

Sarbolandi, H., Lefloch, D. Kolb, A, 2015. Kinect range sensing: structured-light versus time-of-flight kinect. Comput. Vis. Image Underst. 139, 1-20. http:// dx.doi.org/10.1016/j.cviu.2015.05.006.

Shikdar, A.A., Al-Hadhrami, M., 2007. Smart workstation design: an ergonomics and methods engineering approach. Int. J. Ind. Syst. Eng. 2, 363-374. http:/ dx.doi.org/10.1504/IJISE.2007.013184.

Shikdar, A.A., Al-Hadhrami, M., 2012. Evaluation of a low-cost ergonomically designed adjustable assembly workstation. Int. J. Ind. Syst. Eng. 10, 153-166. http://dx.doi.org/10.1504/IJISE.2012.045178.

Shikdar, A.A., Al-Kindi, M.A., 2007. Office ergonomics: deficiencies in computer workstation design. Int. J. Occup. Saf. Ergon. 13, 215-223. http://dx.doi.org $10.1080 / 10803548.2007 .11076722$.

Shinde, G.V., Jadhav, V.S., 2012. Ergonomic analysis of an assembly workstation to identify time consuming and fatigue causing factors using application of motion study. Int. J. Eng. Technol. 4, 220-227.

Spector, J.T., Lieblich, M., Bao, S., McQuade, K., Hughes, M., 2014. Automation of workplace lifting hazard assessment for musculoskeletal injury prevention. Ann. Occup. Environ. Med. 26, 15. http://dx.doi.org/10.1186/2052-4374-26-15.

Srinivas, M., Patnaik, L.M., 1994. Genetic algorithms: a survey. Comput. (Long. Beach. Calif.) 27. http://dx.doi.org/10.1109/2.294849.

Tam, K.Y., 1992. Genetic algorithms, function optimization, and facility layout design. Eur. J. Oper. Res. 63, 322-346. http://dx.doi.org/10.1016/0377-2217(92) 90034-7.

Tompkins, J.A., White, J.A., Bozer, Y.A., Tanchoco, J.M.A., 2010. Facilities Planning, fourth ed. John Wiley \& Sons.

Trask, C., Mathiassen, S., 2012. Data collection costs in industrial environments for three occupational posture exposure assessment methods. BMC Med. Res. Methodol. 12, 89.

Xu, X., McGorry, R.W., 2015. The validity of the first and second generation Microsoft Kinect for identifying joint center locations during static postures. Appl. Ergon. 49, 47-54. http://dx.doi.org/10.1016/j.apergo.2015.01.005.

Yang, L., Zhang, L., Dong, H., Alelaiwi, A., Saddik, A., 2015. Evaluating and improving the depth accuracy of Kinect for Windows v2. IEEE Sens. J. 15, 4275-4285. http://dx.doi.org/10.1109/JSEN.2015.2416651.

Zha, X.F., 2003. Soft computing framework for intelligent human-machine system design, simulation and optimization. Soft Comput. - a Fusion Found. Methodol. Appl. 7, 184-198. http://dx.doi.org/10.1007/s00500-002-0196-4.

Zha, X.F., Lim, S.Y.E., 2003. Intelligent design and planning of manual assembly workstations: a neuro-fuzzy approach. Comput. Ind. Eng. 44, 611-632. http:// dx.doi.org/10.1016/S0360-8352(02)00238-3.

Zhang, L., Sturm, J., Cremers, D., Lee, D., 2012. Real-time human motion tracking using multiple depth cameras. In: Intelligent Robots and Systems (IROS), 2012 IEEE/RSJ International Conference on. IEEE, pp. 2389-2395. http://dx.doi.org 10.1109/IROS.2012.6385968. 